\title{
Effects of weight loss on renal function in overweight Japanese men
}

\author{
Kazuko Masuo $^{1,2}$, Hiromi Rakugi ${ }^{3}$, Toshio Ogihara ${ }^{3}$, Murray D Esler ${ }^{1,4}$ and Gavin W Lambert ${ }^{1,4}$
}

Obesity is known as an independent risk factor for renal injury. Sympathetic nerve activation may have an important role of the pathogenesis of obesity, and hypertension may underpin the development of cardiovascular events. In the present study, we evaluated the effects of weight loss (WL) on renal function, especially focusing on sympathetic nervous activity. In 154 overweight or obese Japanese men ( 89 normotensive and 65 untreated mild hypertensive subjects), body weight, body mass index (BMI), total body fat mass, blood pressure (BP), serum creatinine, blood urea nitrogen, creatinine clearance (CCr) (calculated with the Cockcroft-Gault equation) and plasma norepinephrine (NE) were measured before and after a 12-month period of WL with a mild caloric-restricted diet and exercise. A significant WL was defined as $10 \%$ or more WL compared with the entry period. In total, 97 (63.0\%) subjects succeeded in significant (by $14.3 \%$ ) WL at 12 months, and 57 subjects ( $37.0 \%$ ) did not succeed in significant WL but they lost $7.7 \%$ weight. At entry, levels of plasma NE, serum creatinine and fat mass were significantly lower and CCr was greater in the group with a significant WL compared with those without WL. BMI, total body fat mass and plasma NE significantly decreased, and $\mathrm{CCr}$ increased with WL. At both baseline and at the 12-month period, fat mass and plasma NE negatively correlated with $\mathrm{CCr}$ and positively correlated with creatinine at each time point. Changes in fat mass and plasma NE over 12 months correlated with changes in creatinine, and only changes in fat mass negatively correlated with changes in $\mathrm{CCr}$. Basal fat mass and plasma NE correlated positively with serum creatinine at 12 months and negatively with $\mathrm{CCr}$ at the same time point. In multiple regression analyses, basal plasma NE and fat mass were significant determinants of serum creatinine levels and $\mathrm{CCr}$ at 12 months. In conclusion, WL improved renal function (as evident from measures of creatinine and $\mathrm{CCr}$ ) in overweight individuals. Basal plasma NE levels and total body fat mass could be predictors for improvement in renal function associated with WL. Suppression of sympathetic nervous activation associated with WL may have a role in the ameliorative effects on renal function.

Hypertension Research (2011) 34, 915-921; doi:10.1038/hr.2011.47; published online 12 May 2011

Keywords: creatinine clearance; obesity; renal function; sympathetic nervous system activity; weight loss

\section{INTRODUCTION}

Obesity is a major and growing health problem. ${ }^{1,2}$ The presence of increased adiposity is associated with elevated risk of development of cardiovascular and renal complications. ${ }^{2-4}$ Evidence from several studies indicates that obesity and weight gain are associated with an increased risk of hypertension and diabetes. ${ }^{1,2,5,6}$ Furthermore, several large cohort studies have demonstrated close associations between obesity, especially abdominal obesity and the onset of chronic kidney disease $(\mathrm{CKD})^{7-11}$ and faster CKD progression. ${ }^{10}$ Intentional weight loss (WL) reduced the risk of the onset and development of hypertension, ${ }^{12,13}$ diabetes $^{14}$ and renal injury ${ }^{15}$ in overweight or obese individuals.

The sympathetic nervous system has an important role in the regulation of energy expenditure, and reduced energy expenditure and resting metabolic rate are predictive of weight gain (obesity). In many clinical and epidemiological studies, elevated sympathetic nervous activity has been documented in obesity ${ }^{16}$ or weight gain ${ }^{17-19}$ and in patients with end-stage renal disease. ${ }^{7,20-22}$ Zoccali et al. ${ }^{20,22}$ reported that the degree of sympathetic nervous activation might relate to the occurrence of fatal cardiovascular events. We also observed previously that ${ }^{23}$ higher plasma NE levels could predict future renal injury in non-obese, normotensive individuals. Thus, one could speculate that sympathetic nervous activation might be the trigger linking obesity to impairment in renal function.

Weight loss is recommended as the first-line treatment for obesity. Many large studies ${ }^{24-26}$ have shown marked clinical benefits of lifestyle intervention, and modest $\mathrm{WL}$, on the resolution of obesity-relate diseases including CKD as well as long-term benefits on all-cause mortality. In obese subjects, obesity-related glomerular hyperfiltration, ${ }^{27}$ elevated sympathetic nervous activity, ${ }^{12,13,28-30}$ insulin resistance and stimulation of the renin-angiotensin-aldosterone system $(\mathrm{RAS})^{30,31}$ are ameliorated after WL.

${ }^{1}$ Human Neurotransmitters Laboratory, Melbourne, Victoria, Australia; ${ }^{2}$ Nucleus Network Ltd, Baker IDI Heart and Diabetes Institute, Melbourne, Victoria, Australia; ${ }^{3}$ Department of Geriatric Medicine and Nephrology, Osaka University Graduate School of Medicine, Suita, Osaka, Japan and ${ }^{4}$ Nursing and Health Services, Faculty of Medicine, Monash University, Melbourne, Victoria, Australia

Correspondence: Professor K Masuo, Baker IDI Heart and Diabetes Institute, 75 Commercial Road, Melbourne, Victoria 3004, Australia.

E-mail: kazuko.masuo@bakeridi.edu.au

Received 4 January 2011; revised 2 February 2011; accepted 6 February 2011; published online 12 May 2011 
Many epidemiological and clinical studies have shown the presence of microalbuminuria ${ }^{32,33}$ or proteinuria ${ }^{15}$ as a marker of cardiovascular risks, however, Farbom et al. ${ }^{34}$ reported that microalbuminuria and renal function (creatinine, blood urea nitrogen and creatinine clearance (CCr)) are independently associated with future cardiovascular events. The decrease in CCr (glomerular filtration rate, GFR) was a precursor for the future cardiovascular events. ${ }^{34}$ However, only few investigators have simultaneously taken into account the sympathetic nervous activity and renal function in the same study population, followed longitudinally to evaluate the relationships of sympathetic nervous activity with renal function during WL with life-style modifications. $^{30,35}$

In the present study, using plasma NE levels as a marker of sympathetic activity we evaluated the role of the sympathetic nervous system on renal function (measured serum creatinine and CCr) during WL over a 12-month period with mild caloric restriction and exercise (life-style modification).

\section{METHODS}

\section{Subjects}

The WL program enrolled 154 overweight $\left(25 \mathrm{~kg} \mathrm{~m}^{-2} \leqslant\right.$ body mass index $(\mathrm{BMI})<30 \mathrm{~kg} \mathrm{~m}^{-2}$ ) men, consisting of 89 overweight normotensive (blood pressure (BP) $<140 / 90 \mathrm{~mm} \mathrm{Hg}$ ) and 65 overweight, untreated mildly hypertensive men $(140 / 90 \mathrm{mmHg} \leqslant \mathrm{BP}<160 / 95 \mathrm{~mm} \mathrm{Hg})$ with normal renal function (serum creatinine levels $<1.5 \mathrm{mg} \mathrm{dl}^{-1}, \mathrm{CCr}>80 \mathrm{ml}$ per min, negative proteinuria or negative albuminuria by dipstick test). None of the subjects had diabetes (fasting blood glucose level $<100 \mathrm{mg} \mathrm{dl}^{-1}$ and hemoglobin Alc $<6.0 \%$ ) or other illnesses, including psychological or emotional problems ${ }^{36}$ or obstructive sleep apnea. ${ }^{37}$ No subjects were taking antihypertensive agents or other medications. Only subjects whose body weight had not changed for at least the previous 1 year (weight change $<5 \%$ provided in their biannual medical evaluation records) were enrolled in the present study. ${ }^{17,29}$ The protocol was approved by the ethics committee of Osaka University Graduate School of Medicine, Japan, and written informed consent was obtained from all the subjects.

\section{Study design}

The WL program consisted of a mild caloric restricted diet ( $1800 \mathrm{kcal}$ per day, $55 \%$ of calorie from carbohydrate, $30 \%$ from protein and $15 \%$ from fat), low sodium diet $(7 \mathrm{~g} \mathrm{NaCl}$ per day) and aerobic exercise of more than $1 \mathrm{~h}$ daily (e.g., walking, jogging or gym exercise). The subjects attended a 1-h private counseling session each week for 4 weeks followed by biweekly $1 \mathrm{~h}$ sessions for an additional 11 months. All session were led by experts in nutrition and exercise counseling. Calorie intake was calculated based on the subjects' meal diary, which was assessed by trained nutritionists. The physical activity was quantified and recorded by the use of pedometers on a daily basis. Diet and exercise compliance were measured according to the subjects' own records every 2 weeks.

\begin{abstract}
Measurements
Data including height, body weight, BMI, percentage total body fat mass, waist circumference, hip circumference and urinalysis were determined in the morning after an overnight fast of $12 \mathrm{~h}$. After $30 \mathrm{~min}$ rest in the supine position, BP, heart rate and venous blood sampling for measurements of blood urea nitrogen, creatinine, glucose, plasma norepinephrine (NE) were obtained. Samples were taken at baseline and at 12 months during the study. BP and heart rate were measured more than three times in the supine position by an automated sphygmomanometer (TM-2713, A\&D, Tokyo, Japan) using an adjusted cuff size, based on arm circumference. Recorded BP levels and heart rates were averaged. The percentage body fat mass was determined by impedance measurements (BF-102, Tanita, Tokyo, Japan). Total body fat mass (kg) was calculated according to the following formula: (percentage body fat mass $(\%) / 100) \times$ body weight $(\mathrm{kg})$. Plasma NE was measured by the methods previously reported. ${ }^{29}$ Creatinine clearance was calculated by the Cockcroft-
\end{abstract}

Gault equation as an estimated GFR: $(140-$ age $) \times($ weight in $\mathrm{kg}) / 72 \times($ creatinine in $\left.\mathrm{mg} \mathrm{dl}^{-1}\right) .^{38}$

\section{Statistical analyses}

Values are shown as mean \pm s.d. All data analyses were performed with SPSS 8.0 for Windows program (SPSS Inc., Chicago, IL, USA). Changes in measured parameters within each group and differences among groups were examined by two-way analysis of variance. When these differences were significant, post hoc analysis was performed using Dunnett's test. Prevalence of hypertension was estimated using the $\chi^{2}$-test. Associations between selected variables were analyzed with Pearson product-moment correlations. Multiple linear regression analyses were used to examine relations among variables using serum creatinine levels or $\mathrm{CCr}$ at the 12-month period as independent variables $v s$. changes in BMI, total body fat mass, waist circumference, waist-to-hip ratio, BP changes and hormonal measurements as dependent variables.

\section{RESULTS}

Prevalence of significant weight loss at 6 and 12 months

When significant WL was defined as a $10 \%$ or more reduction in BMI from baseline, 97 subjects $(63.0 \%)$ succeeded in achieving significant WL, with the WL being $14.3 \%$. Fifty-seven subjects (37.0\%) did not succeed in significant WL at 12 months, but all of them lost weight by $7.7 \%$, and all subjects lost weight more than $5 \%$. The group with significant WL included 60 normotensive and 37 hypertensive subjects at the baseline period, and 85 normotensive and 12 hypertensive subjects at 12 months. The group that did not lose weight significantly at 12 months included 29 normotensive and 28 hypertensive subjects at the baseline period and 39 normotensive and 18 hypertensive subjects at 12 months. There was no statistical significance in the prevalence of hypertension between the groups with and without significant $\mathrm{WL}$ at the baseline period $\left(\chi^{2}=1.774\right.$, not significant $)$; however at 12 months, after $\mathrm{WL}$, the group who succeeded in significant WL contained higher frequency of normotensive subjects $\left(\chi^{2}=8.445, P<0.01\right)($ Table 1$)$.

\section{Calorie intake and physical activity}

Diet compliance (calorie intake), physical activity (steps per day), behavior (alcohol intake, cigarette smoking) and socioeconomic status were similar between the two study groups throughout the study (Table 1). Diet and exercise compliance were assessed from the subjects' own records every 2 weeks, which were recorded at private counseling sessions. Compliance to diet and exercise was considered excellent and consistent, based on those records over the 12-month period. There were no significant differences in these confounders between the groups with and without significant WL at 12 months.

\section{Characteristics of subjects with significant weight loss}

Subjects who succeeded in significant WL $(\geqslant 10 \%)$ compared with baseline BMI had significantly lower total body fat mass amounts, lower levels of plasma NE and serum creatinine and greater $\mathrm{CCr}$ at the baseline period compared with those without significant WL, although BMI, lean body mass, waist-to-hip ratio, BP levels and blood urea nitrogen at the baseline period were similar (Table 1). Importantly, calorie intake and physical activity, as assessed using pedometers were similar between the two groups at both baseline and at 12 months. All parameters, except CCr, significantly decreased at 12 months compared with those at the baseline period in both groups, and CCr increased significantly even in the group without significant WL. Even in subjects who did not succeed in significant WL, those parameters changed significantly from the baseline values, although absolute and percent changes in these parameters in the group without significant WL were smaller than those with significant WL (Table 1). 
Table 1 Characteristics of subjects with and without significant weight loss at 12 months

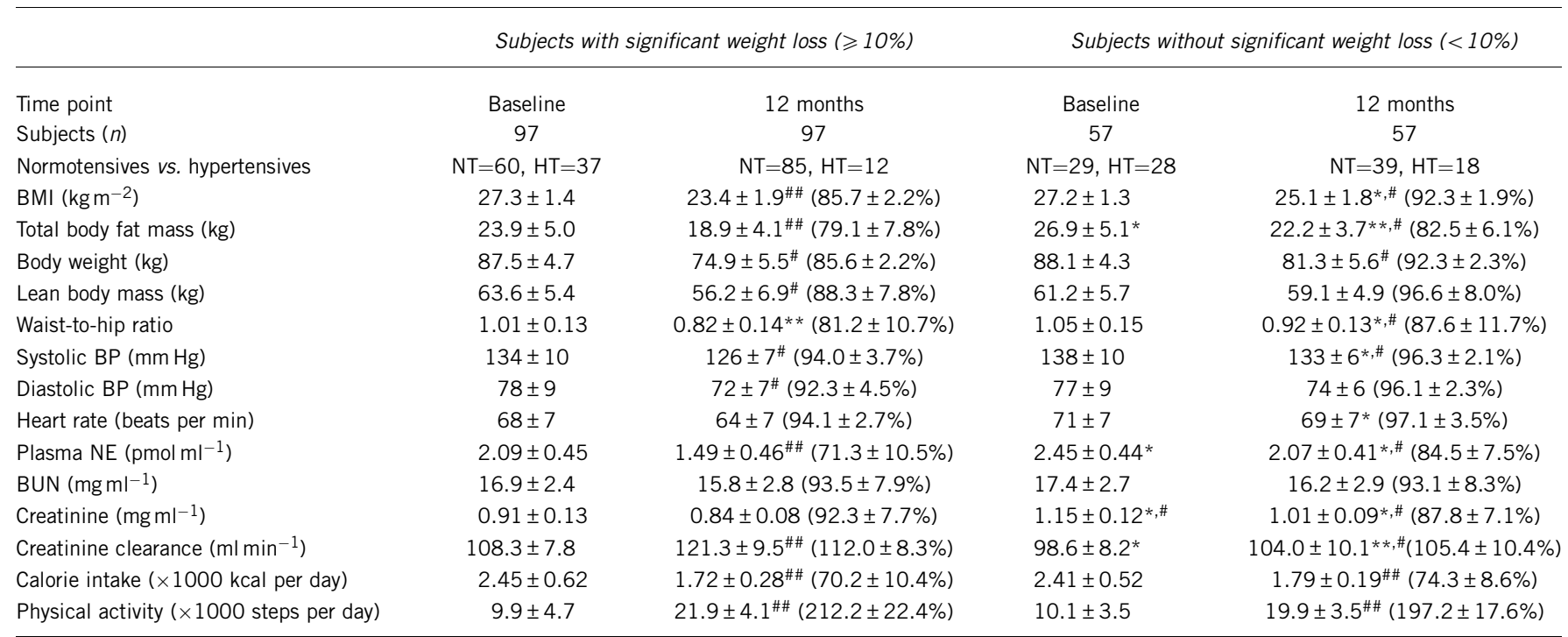

Abbreviations: BMI, body mass index; BP, blood pressure; BUN, blood urea nitrogen; HOMA-IR, homeostasis model of insulin resistance; HT, hypertensive subjects; NE, norepinephrine; NT, normotensive subjects; WL, weight loss.

(\%) Percent in parenthesis shows percent changes compared with the values at the baseline period in each group.

${ }^{*} P<0.05,{ }^{*} P<0.01$ vs. values in subjects with significant weight loss; ${ }^{\#} P<0.01,{ }^{\#} P<0.01$ vs. values at entry period.

\section{Correlations between total body fat mass, plasma NE, serum creatinine and creatinine clearance}

At both periods, total body fat mass and plasma NE levels significantly were positively correlated with serum creatinine levels (Figure 1), and negatively with CCr (Figure 2). Changes in total body fat mass correlated positively with changes in serum creatinine levels over 12 months and negatively with changes in CCr over 12 months (Figure 3). Creatinine clearance did not improve in several subjects, although serum creatinine decreased in all subjects. Furthermore, decreases in plasma NE over 12 months with WL correlated with decreases in serum creatinine levels, but there was no correlation between changes in plasma NE and changes in $\mathrm{CCr}$ (Figure 3). Basal (i.e., on admission to the study) total body fat mass and basal plasma NE correlated with serum creatinine levels at 12 months $(R=0.4503, P<0.05 ; R=0.4467$, $P<0.05$; respectively), and negatively with $\mathrm{CCr}$ at 12 months ( $R=-0.3386, P<0.05 ; R=-0.3399, P<0.05$; respectively) (Figure 4).

\section{Multiple regression analyses}

In multiple linear regression analyses, using serum creatinine level at a 12-month period as an independent variable, basal total body fat-mass $\left(R^{2}=0.3158, P<0.05\right)$, basal plasma NE $\left(R^{2}=0.2944, P<0.05\right)$ and basal serum creatinine $\left(R^{2}=0.3542, P<0.05\right)$ were significant determinant variables. When $\mathrm{CCr}$ at 12 months was used as an independent variable, basal total body fat mass $\left(R^{2}=0.3675, P<0.05\right)$, basal plasma NE levels $\left(R^{2}=0.3327, P<0.05\right)$, basal $\operatorname{CCr}\left(R^{2}=0.4579, P<0.05\right)$, changes in total body fat mass $\left(R^{2}=0.4123, P<0.05\right)$ and changes in plasma NE levels $\left(R^{2}=0.3656, P<0.05\right)$ were significant predictive variables.

\section{DISCUSSION}

The main findings in the present report were that: (1) subjects who succeed with significant WL $(\geqslant 10 \%)$ over a 12 -month period have initial lower total body fat mass, plasma $\mathrm{NE}$ and serum creatinine levels and greater CCr compared with subjects who failed to lose significant weight, (2) even in subjects who failed to lose weight significantly, serum creatinine and CCr improved in response to $\mathrm{WL}$ as did plasma NE levels, (3) initial total body fat mass and plasma NE levels correlated with serum creatinine levels and CCr at the 12-month follow-up period and (4) changes in plasma NE with WL over 12 months correlated with reductions in creatinine levels, whereas reductions in total body fat mass correlated with reductions in serum creatinine levels and improvement in CCr. These findings demonstrate that WL improves renal function, as evident from measures of serum creatinine and $\mathrm{CCr}$, even in subjects whose WL was modest and who initially had normal renal function. The improvement in $\mathrm{CCr}$ was predicted by initial total body fat mass and plasma NE levels. In overweight subjects with normal renal function, $\mathrm{CCr}$ (calculated with the Cockcroft-Gault equation) was, at least partially, determined by adiposity and sympathetic nervous activity.

Obesity, which is frequently associated with sympathetic nervous activation, is an important factor in the progression and perhaps even in the initiation of $\mathrm{CKD},{ }^{39,40}$ and abdominal obesity is a relevant risk factor for death and cardiovascular complications in those with CKD. ${ }^{20,41}$ Obesity, itself, contributes to the development and progression of CKD, independent of elevated BP or diabetes. ${ }^{42}$ The risk for end-stage renal disease is progressively higher at increasing BMI levels and in extremely obese individuals in which such risk is much higher than that in persons with normal BMI. ${ }^{41}$ Elevated sympathetic nervous activity has been observed in patients with $\mathrm{CKD}$, regardless of obesity, hypertension or diabetes. ${ }^{11,16,20}$ Our earlier study showed that high plasma NE levels could predict future renal injury even in non-obese, normotensive subjects. ${ }^{23}$ In addition, we reported in a recent study that WL might contribute to the improvement in renal function that accompanies suppression of muscle sympathetic nerve activity in obese subjects with metabolic syndrome. ${ }^{30}$ In the present study, we observed that long-term WL, even mild or moderate, was associated with a reduction in sympathetic activity with concomitant improvement in renal function, as assessed from measures of serum creatinine and estimated CCr. Taken together, activation of the sympathetic nervous system is an important factor in the onset and development of obesity-related renal injury, ${ }^{7,20,22,23}$ and hence $\mathrm{WL}$ 

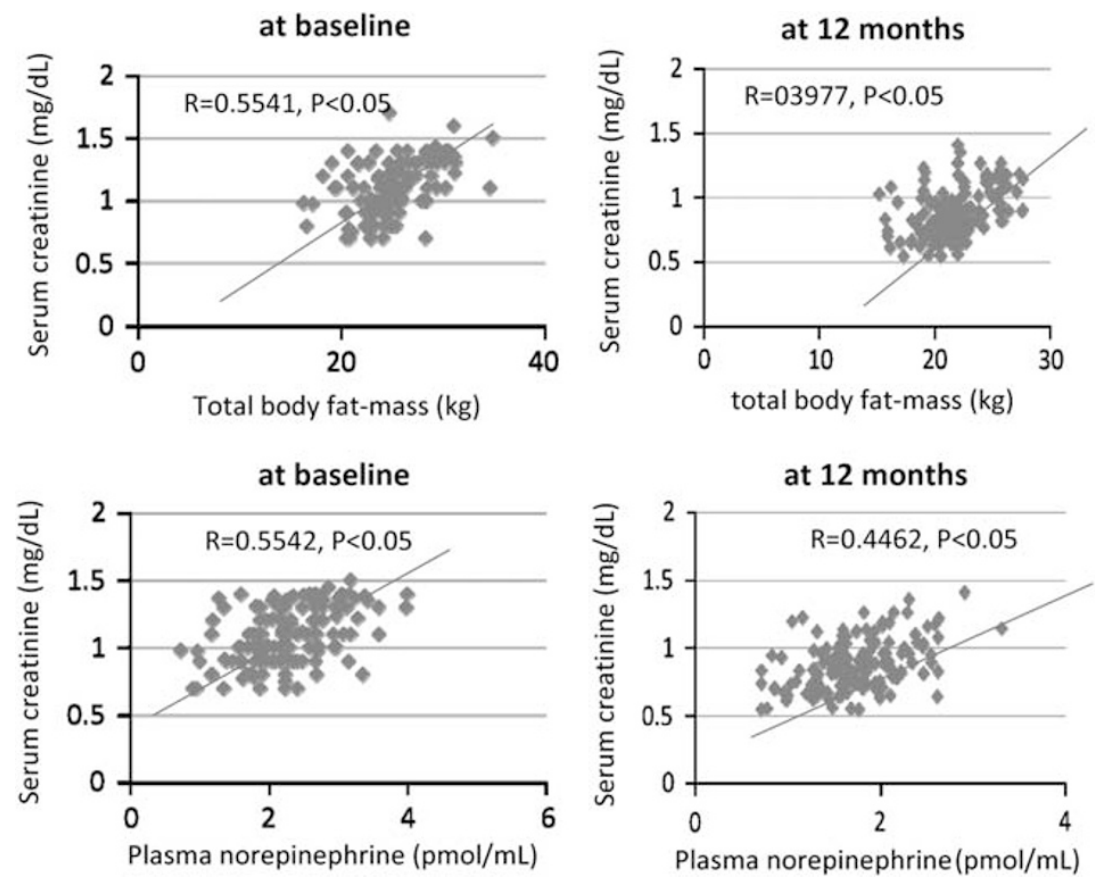

Figure 1 Upper panels, correlations between total body fat mass and serum creatinine levels at the baseline period (upper-left panel) and at 12 months (upper-right panel). Lower panels, correlations between plasma norepinephrine levels and serum creatinine levels at the baseline period (lower-left panel) and at 12 months (lower-right panel).
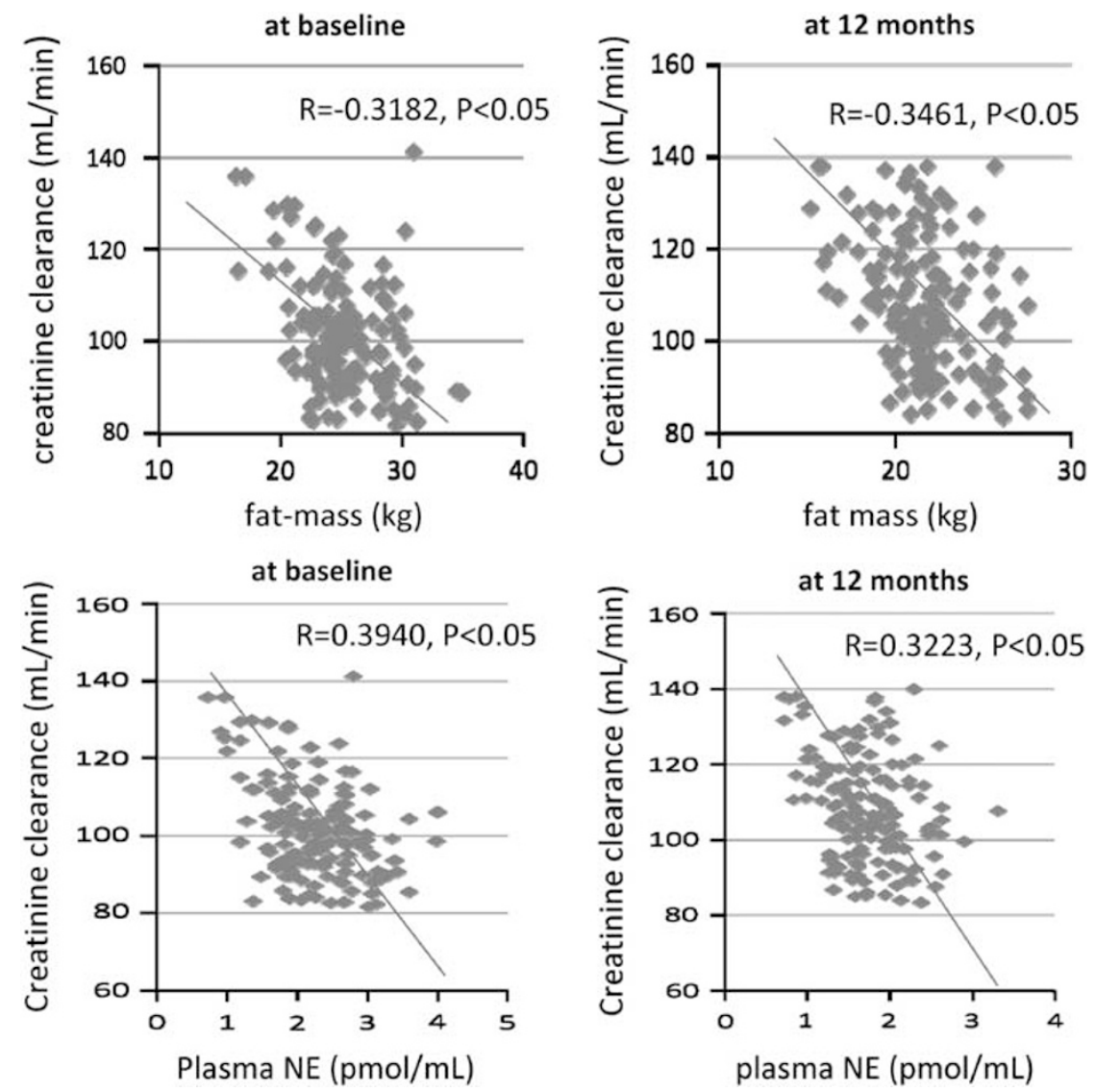

Figure 2 Upper panels, correlations between total body fat mass and creatinine clearance ( $\mathrm{CCr}$ ) at the baseline period (upper-left panel) and at 12 months (upper-right panel). Lower panels, correlations between plasma norepinephrine (NE) levels and $\mathrm{CCr}$ at the baseline period (lower-left panel) and at 12 months (lower-right panel). 

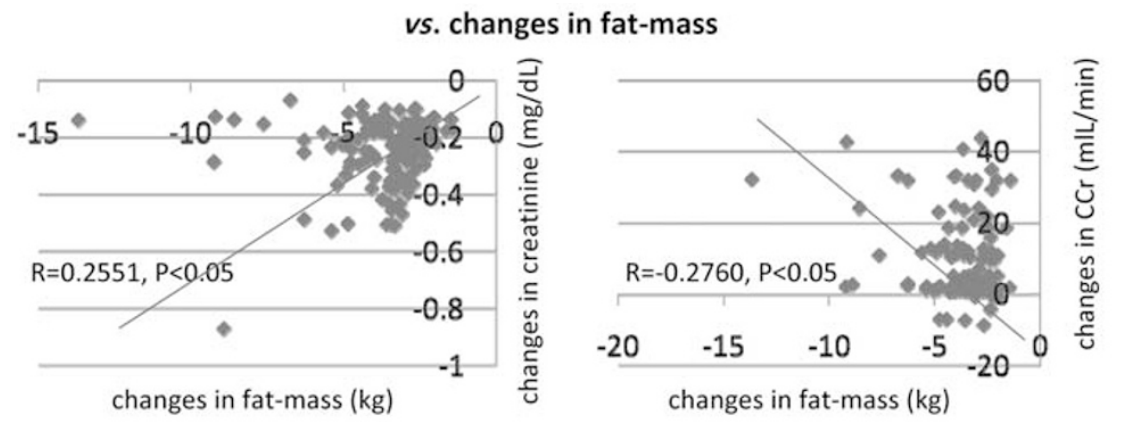

\section{vs. changes in plasma NE}
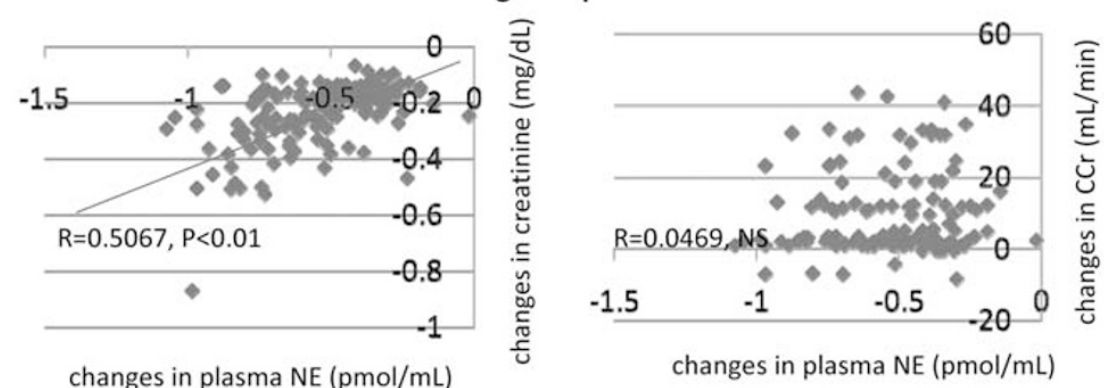

Figure 3 Upper panels, correlations between changes in total body fat mass over 12 months and changes in serum creatinine levels over 12 months (upperleft panel) and between changes in total body fat mass over 12 months and changes in creatinine clearance (CCr) over 12 months (upper-right panel). Lower panels, correlations between changes in plasma norepinephrine (NE) levels over 12 months and changes in serum creatinine levels over 12 months (lowerleft panel), and between changes in plasma NE levels over 12 months and changes in $\mathrm{CCr}$ over 12 months (lower-right panel).

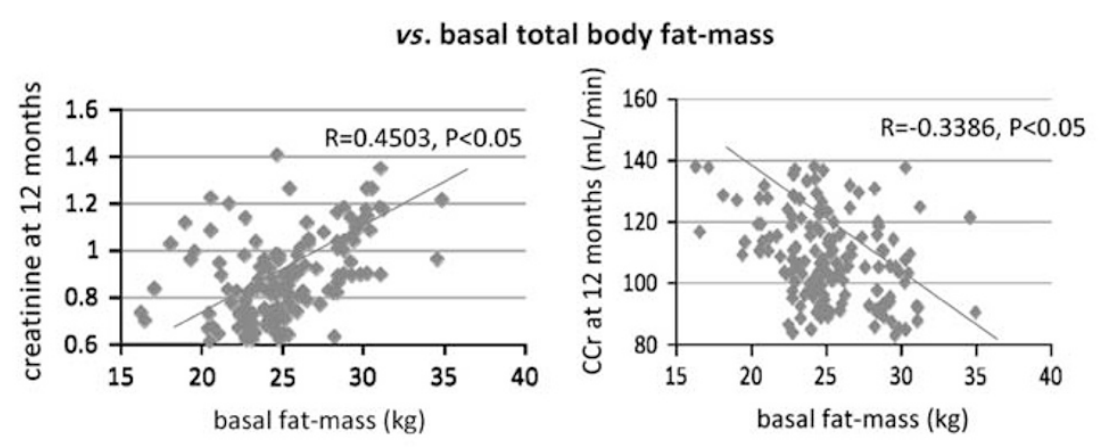

vs. basal plasma NE
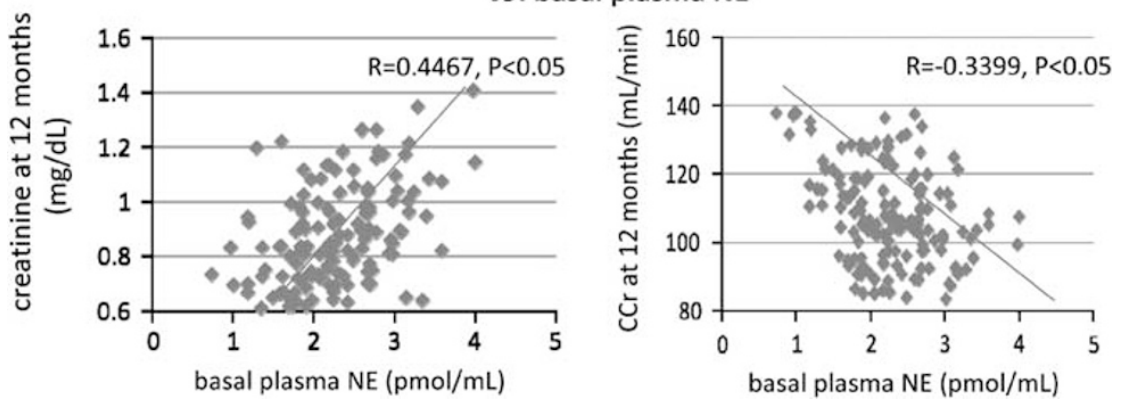

Figure 4 Upper panels, correlations between basal total body fat mass and serum creatinine levels at 12 months (upper-left panel), and between basal total body fat mass and creatinine clearance (CCr) at 12 months (upper-right panel). Lower panels, correlations between basal plasma norepinephrine (NE) levels and serum creatinine levels at 12 months (lower-left panel), and between basal plasma NE levels and $\mathrm{CCr}$ at 12 months (lower-right panel).

programs should be initiated and convey some degree of renal protection in the overweight/obese patient.

Glomerular hyperfiltration, ${ }^{41}$ hyperleptinemia, ${ }^{43,44}$ insulin resistance $^{30}$ and stimulation of the RAS, ${ }^{21,45}$ accompanying heightened sympathetic nervous activity, may contribute to renal injury in obesity. It has been documented that the RAS is linked to obesity and its activity is reduced in association with WL. ${ }^{46,47}$ Such reduction in RAS is important for renal protection. ${ }^{48,49} \mathrm{~A}$ recent study by our group in 
Caucasian subjects demonstrated that exercise, but not calorie restriction, contributed more to improvements in renal function and suppression of plasma renin activity. ${ }^{30}$ In the present study, we did not measure RAS parameters, and hence cannot unequivocally assess the contributions of the RAS on renal function improvement. In addition, we previously reported that only plasma NE, but not homeostasis model assessment-insulin resistance or leptin, ${ }^{23}$ could predict future renal injury in non-obese, normotensive subjects. It would seem, therefore, that the contributions of insulin resistance or hyperleptinemia on renal function seem not to be as strong as the influence of sympathetic nervous activation.

Many studies have shown that the early increases in GFR that occur with weight gain (obesity) are compensatory. ${ }^{48}$ The decrease in GFR and arterial pressure after WL is comparable with this hypothesis. Chagnac et al., ${ }^{15}$ however, reported that obesity-related glomerular hyperfiltration was improved after WL in morbidly obese subjects as assessed using insulin and p-aminohippuric acid clearance. In the present study, we also observed that several subjects did not improve CCr as calculated using the Cockcroft-Gault equation, even though their creatinine levels decreased with WL. This might be related to irreversible glomerular hyperfiltration, due to obesity or hypertension, but we cannot exclude that it occurs as result of limitations of the Cockcroft-Gault equation (as discussed in the next paragraph).

In the present study, we used serum creatinine concentration and $\mathrm{CCr}$ with the Cockcroft-Gault equation as markers of renal function. The National Kidney Foundation in the United States currently recommends using a CCr, based estimate of GFR (i.e., Modification of Diet in Renal Disease formula), and has advocated the use of a standardized classification for CKD. Furthermore, Cockcroft et al. ${ }^{38}$ assessed the accuracy of the equation to be in around $70 \%$ agreement in subjects with normal CCr (normal renal function), although, particularly in patients with a CCr below $50 \mathrm{ml} \mathrm{min}^{-1}$, overall accuracy of the equation is substantially diminished, because creatinine is removed not only by glomerular filtration but also by renal tubular secretion. ${ }^{50}$ Thus, CCr with the Cockcroft-Gault equation may obscure the genuine association between renal function and $\mathrm{WL}$ (adiposity) in subjects with normal renal function, ${ }^{51}$ although CCr with the Cockcroft-Gault equation in mild-to-moderate renal injury cannot reflect renal functions accurately. In this study all subjects had $>80 \mathrm{ml} \mathrm{min}^{-1}$ of CCr without proteinuria or $>1.5 \mathrm{mg} \mathrm{dl}^{-1}$ of serum creatinine (normal renal function).

Serum creatinine and estimated CCr were ameliorated with WL in the present study. Estimation of renal function is better using a serum creatinine-based formula than individual serum creatinine values, ${ }^{52}$ because serum creatinine levels are more dependent on creatinine production, mainly in muscle. However, when we analyzed the relationships with renal function using lean body mass, which is more related with muscle than fat mass, serum creatinine and creatinine clearance did not correlate significantly with lean body mass, suggesting that adiposity accompanying high plasma NE might relate to renal function observed in serum creatinine and CCr. One of the limitations in the present study, however, was that we did not obtain measurements of cystatin $\mathrm{C}$, which is documented as a marker of renal function that is less sensitive to changes in muscle mass. ${ }^{50}$

\section{CONCLUSION}

The present study demonstrated that a WL program with mild caloric restriction diet and exercise had an ameliorative effect on renal function in overweight subjects, with initially normal renal function. Initial total body fat mass and plasma NE were predictors of renal function ( $\mathrm{CCr}$ and serum creatinine) and WL (total body fat mass loss) over a 12-month period. Furthermore, it should be noted that even in subjects with mild WL over 12 months, renal function, as seen in serum creatinine and CCr, and plasma NE levels improved significantly.

Weight loss has been shown to benefit renal function, ${ }^{14,30,33}$ however the precise mechanisms by which this occurs has not been fully clarified. There are few longitudinal studies of sufficient duration aimed to address the relationships between renal function and the sympathetic nervous activity with WL. Furthermore, previous studies have relied on measures of albuminuria or proteinuria as an index of renal function. This study emphasizes the pivotal role that the sympathetic nervous system has in renal function and highlights its role in ameliorating the effects of WL in obesity.

\section{CONFLICT OF INTEREST}

The authors declare no conflict of interest.

\section{ACKNOWLEDGEMENTS}

Professor Esler and Dr Lambert are supported by the National Health and Medical Research Council of Australia Research Fellowships. The laboratory of Professor Esler and Dr Lambert currently receive research funding from private organisations including ARDIAN, Allergan, Abbott (formerly Solvay) Pharmaceuticals and Scientific Intake. These organizations had no role in this manuscript.

1 Ogden CL, Carroll MD, Curtin LR, McDowell MA, Tabak CJ, Flegal KM. Prevalence of overweight and obesity in the United States, 1999-2004. JAMA 2006; 295: $1549-1555$.

2 Mokdad AH, Ford ES, Bowman BA, Dietz WH, Vinicor F, Bales VS, Marks JS. Prevalence of obesity, diabetes, and obesity-related health risk factors, 2001. JAMA 2003; 289: 76-79.

3 Preis SR, Hwang SJ, Coady S, Pencina MJ, D’Agostino Sr RB, Savage PJ, Levy D, Fox CS. Trends in all-cause and cardiovascular disease mortality among women and men with and without diabetes mellitus in the Framingham Heart Study, 1950 to 2005. Circulation 2009; 119: 1728-1735.

4 Elsayed EF, Tighiouart H, Weiner DE, Griffith J, Salem D, Levey AS, Sarmak MJ. Waist-to-hip ratio and body mass index as risk factors for cardiovascular events in CKD. Am J Kidney Dis 2008; 52: 49-57.

5 Ford ES, Williamson DF, Liu S. Weight change and diabetes incidence: findings from a national cohort of US adults. Am J Epidemiol 1997; 146: 214-222.

6 Resnick HE, Valsania P, Halter JB, Lin X. Relation of weight gain and weight loss on subsequent diabetes risk in overweight adults. J Epidemiol Communuty Health 2000; 54: 596-602.

7 Masuo K, Rakugi H, Ogihara T, Esler MD, Lambert GW. Cardiovascular and renal complications of type 2 diabetes in obesity: role of sympathetic nerve activity and insulin resistance. Curr Diabetes Rev 2010; 6: 58-67.

8 Luk AO, So WY, Ma RC, Kong AP, Ozaki R, Ng VS, Yu LW, Lau WW, Yang X, Chow FC, Chan JC, Tong PC, Hong Kong Diabetes Registry. Metabolic syndrome predicts new onset of chronic kidney disease in 5,829 patients with type 2 diabetes: a 5-year prospective analysis of the Hong Kong Diabetes Registry. Diabetes Care. 2008; 31: 2357-2361.

9 Noori N, Hosseinpanah F, Nasiri AA, Azizi F. Comparison of overall obesity abd abdominal adiposity in predicting chronic kidney disease incidence among adults. J Ren Nutr 2000; 19: 228-237.

10 Othman M, Kawar B, EI Nahas AM. Influence of obesity on progression of non-diabetic chronic kidney disease: a retrospective cohort study. Nephron Clin Pract 2009; 113: c16-c23.

11 Masuo K, Lambert GW, Esler MD, Rakugi H, Ogihara T, Schlaich MP. The role of sympathetic nervous activity in renal injury and end-stage renal disease. Hypertens Res 2010; 33: 521-528.

12 Masuo K. Obesity-related hypertension: role of sympathetic nervous system, insulin, and leptin. Curr Hypertens Rep 2002; 4: 112-118.

13 Straznicky NE, Lambert GW, McGrane MT, Masuo K, Dawood T, Nestle PJ, Eikelis N, Schlaich MP, Esler MD, Socratous F, Chopra R, Lambert EA. Weight loss may reserve blunted sympathetic neural responsiveness to glucose ingestion in obese subjects with metabolic syndrome. Diabetes 2009; 58: 1126-11342.

14 Will JC, Williamson DF, Ford ES, Calle EE, Thun MJ. Intentional weight loss and 13-year diabetes incidence in overweight adults. Am J Public Health 2002; 92: 1245-1248.

15 Chagnac A, Weinstein T, Herman M, Hirsh J, Gafter U, Ori Y. The effects of weight loss on renal function in patients with severe obesity. J Am Soc Nephrol 2000; 14: 1480-1486 
16 Esler M, Straznicky N, Eikelis N, Masuo K, Lambert G, Lambert E. Mechanisms of sympathetic activation in obesity-related hypertension. Hypertension 2006; 48 : 787-796.

17 Masuo K, Mikami H, Ogihara T, Tuck ML. Weight gain-induced blood pressure elevation. Hypertension 2000; 35: 1135-1140.

18 Masuo K, Katsuya T, Fu Y, Rakugi H, Ogihara T, Tuck ML. Beta2-and beta3-adrenergic receptor polymorphisms are related to the onset of weight gain and blood pressure elevation over 5 years. Circulation 2005; 111: 3429-3434.

19 Masuo K, Kawaguchi H, Mikami H, Ogihara T, Tuck ML. Serum uric acid and plasma norepinephrine concentrations predict subsequent weight gain and blood pressure elevation. Hypertension 2003; 42: 474-480.

20 Zoccali C, Mallamaci F, Tripepi G, Parlongo S, Cutrupi S, Benedetto FA, Cataliotti A, Malatino S. Norepinephrine and concentric hypertrophy in patients with end-stage renal disease. Hypertension 2002; 40: 41-46.

21 Schlaich MP, Socratous F, Hennebry S, Eikelis N, Lambert EA, Straznicky N, Esler MD, Lambert GW. Sympathetic activation in chronic renal failure. J Am Soc Nephrol 2009, 20: 933-939.

22 Zoccali C, Mallamaci F, Parlongo S, Cutrupi S, Benedetto AB, Tripepi G, Bonanno G, Rapisarda F, Fatuzzo P, Seminara G, Cateliotti A, Stancanelli B, Malatino S. Plasma norepinephrine predicts survival and incident cardiovascular events in patients with end-stage renal disease. Circulation 2002; 105: 1354-1359.

23 Masuo K, Katsuya T, Sugimoto K, Kawaguchi H, Rakugi H, Ogihara T, Tuck ML. High plasma norepinephrine levels associated with $\beta 2$-adrenoceptor polymorphisms predict future renal damage in nonobese normotensive individuals. Hypertens Res 2007; 30: 503-511.

24 Sjostrom L, Narbro K, Sjostrom CD, Karason K, Larsson B, Wedel H, Lystig T, Sullivan M, Bouchard C, Carlsson B, Bengtsson C, Dahlgren S, Gummesson A, Jacobson P, Karlsson J, Lindroos AK, Lönroth H, Näslund I, Olbers T, Stenlöf K, Torgerson J, Agren G, Carlsson LM, Swedish Obese Subjects Study. Effects of bariatric surgery on mortality in Swedish obese subjects. N Engl J Med 2007; 357: 741-752.

25 Orchard TJ, Temprosa M, Goldberg R, Haffner S, Ratner R, Marcovina S, Fowler S. The effect of metformin and intensive lifestyle intervention on the metabolic syndrome: the Diabetes Prevention Program randomized trial. Am Intern Med 2005; 142: 611-619.

26 Anderssen SA, Carroll S, Urdal P, Holme I. Combined diet and exercise intervention reverses the metabolic syndrome in middle-aged males: results from the Oslo Diet and Exercise Study. Scand J Med Sci Sports 2007; 17: 687-695.

27 Hall JE. Renal and cardiovascular mechanisms of hypertension in obesity. Hypertension 1994; 23: 381-394.

28 Grassi G, Seravalle G, Colombo M, Bolla G, Cattaneo BM, Cavagnini F, Mancia G. Body weight reduction, sympathetic nerve traffic, and arterial baroreflex in obese normotensive humans. Circulation 1998; 97: 2037-2042.

29 Masuo K, Katsuya T, Kawaguchi H, Fu Y, Rakugi H, Ogihara T, Tuck ML. Rebound weight gain as associated with high plasma norepinephrine levels that are mediated through polymorphisms in the beta2-adrenoceptor. Am J Hypertens 2005; 18: 1508-1516.

30 Straznicky NE, Grima MT, Lambert EA, Eikelis N, Dawood T, Lambert GW, Nestle PJ, Masuo K, Sari Cl, Chopra R, Mariani JA, Schlaich MP. Exercise augments weight loss induced improvement in renal function in obese metabolic syndrome individuals. J Hypertens 2010, 276.

31 Foster MC, Hwang SJ, Larson MG, Lichtman JH, Parikh NI, Vasan RS, Levy D, Fox CS. Overweight, obesity, and the development of stage 3 CKD: the Framingham Heart Study. Am J Kidney Dis 2008; 52: 39-48.

32 Schrader J, Luders S, kulschewski A, Hammersen F, Zuchner C, Venneklass U, Schrandt G, Schneider M, Rangoonwala B, Berger J, Dominiak P, Zidek W. Microalbuminuria and tubular proteinuria as risk predictors of cardiovascular morbidity and mortality in essential hypertension: final results of a prospective long-term study (MARPLE Study). J Hypertens 2006; 24: 541-548.
33 Yudkin JS, Forrest RD, Jackson CA. Microalbuminuria as predictor of vascular disease in non-diabetic subjects. Islington Diabetes Survey. Lancet 1988; 2: 530-533.

34 Farbom P, Wahlstrand B, Almgren P, Skrtic S, Lanke J, Weiss L, Kjeldsen S, Hender T, Melander 0 . Interaction between renal function and microalbuminuria for cardiovascular risk in hypertension. The Nordic Diltiazem Study.. Hypertension 2008; 52: 115-122.

35 Brinkworth GD, Buckley JD, Moakes M, Clifton PM. Renal function following long-term weight loss in individuals with abdominal obesity on a very-low-carbohydrate diet vs high-carbohydrate diet. J Am Diet Assoc 2010; 110: 633-638.

36 Claesson IM, Josefsson A, Sydsjo G. Prevalence of anxiety and depressive symptoms among obese pregnant and postpartum women: an intervention study. BMC Public Health 2010; 10: 766.

37 Adesseun GA, Rosas SE. The impact of obstructive sleep apnea on chronic kidney disease. Curr Hypertens Rep 2010; 12: 378-383.

38 Shoker A, Hossain MA, Koru-Sengul T, Raju DL, Cockcroft D. Performance of creatinine clearance equations on the original Cockcroft-Gault population. Clin Nephrol 2006; 66: 89-97.

39 Lambert E, Ika Sari C, Dawood T, Nguyen J, McGrane M, Eikelis N, Chopra R, Wong C, Chatzivlastou K, Head G, Straznicky G, Esler M, Schlaich M, Lambert G. Sympathetic nervous system is associated with obesity-induced subclinical organ damage in young adults. Hypertension 2010; 56: 351-358.

40 Lambert GW, Straznicky EA, Dixon JB, Lambert EA, Schlaich MP. Sympathetic nervous and adrenal medullary systems as targets for treatment in metabolic syndromeassociated disorders. Pharmacol and Therapeut 2010; 126: 159-172.

41 Zoccali C. Overweight, obesity and metabolic alteration in chronic kidney disease. Prilozi 2009; 30: 17-31.

42 de Jong PE, Berhave JC, Pinto-Sietsma SI, Hillege HL. Obesity and target organ damage: the kidney. Int J Obes Relat Metab Disord 2002; 26(Suppl 4): S21-S24.

43 Kahatriya S, Reams GP, Spear RM, Freeman RH, Dietz JR, Villarreal D. Obesity hypertension: the emerging role of leptin in renal and cardiovascular dyshomeostasis. Curr Opin Nephrol Hypertens 2010; 19: 72-78.

44 Rahmouni K, Haynes WG. Leptin and the cardiovascular system. Recent Prog Horm Res 2004; 59: 225-244.

45 Straznicky NE, Grima MT, Eikelis N, Nestel PJ, Dawood T, Schlaich MP, Chopra R, Masuo K, Esler MD, Sari CI, Lambert GW, Lambert EA. The effects of weight loss versus weight loss maintenance on sympathetic nervous system activity and metabolic syndrome components. J Clin Endocrinol Metab 2011; 96: E503-E508.

46 Saiki A, Ohira M, Endo K, Koide N, Oyama T, Murano T, Watamabe H, Miyashita $Y$, Shirai K. Circulating angiotensin II is associated with body fat accumulation and insulin resistance in obese subjects with type 2 diabetes. Metabolism 2009; 58: 708-713.

47 Hamada T, Kotani K, Nagai N, Ysuzaki K, Sano Y, Matsuoka Y, Fujibayashi M, Kiyohara N, Tanaka S, Yoshimura M, Egawa K, Kitagawa Y, Kiso Y, Moritani T, Sakane N. Genetic polymorphisms of the renin-angiotensin system and obesity-related metabolic changes in response to low-energy diet in obese women. Nutrition 2011; 27: 34-39.

48 Ahmed SB, Fisher ND, Stevanovic R, Hollenberg NK. Body mass index and angiotensin-dependent control of the renal circulation in healthy humans. Hypertension 2005; 46: $1316-1320$

49 Weir MR. Effects of renin-angiotensin system inhibition on end-organ protection: can we do better? Clin Ther 2007; 29: 1803-1824.

50 Curhan G. Cystatin C: a marker of renal function or something more? Clin Chemist 2004; 51: 293-294.

51 Delanaye P, Radermecker RP, Rorive M, Depas G, Krzesinski JM. Indexing glomerular filtration rate for body surface area in obese patients is misleading: concept and example. Nephrol Dial Transplant 2006; 20: 2024-2028.

52 Lane BR, Poggio ED, Herts BR, Novick AC, Campbell SC. Renal function assessment in the era of chronic kidney disease: renewed emphasis on renal function centered patients care. J Urol 2009; 18: 435-443. 